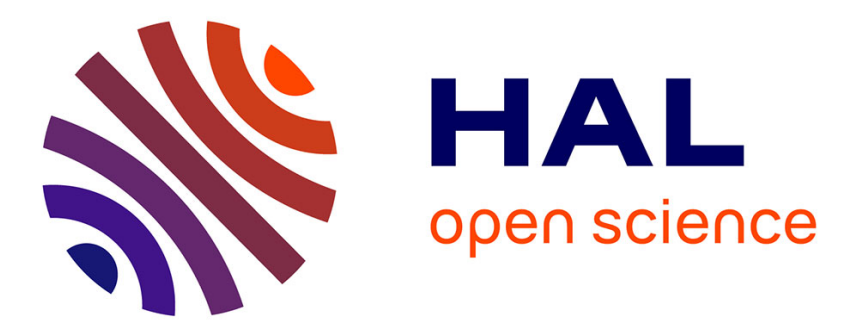

\title{
Laser-powder-material interactions in the laser cladding process
}

\author{
M. Picasso, M. Rappaz
}

\section{To cite this version:}

M. Picasso, M. Rappaz. Laser-powder-material interactions in the laser cladding process. Journal de Physique IV Proceedings, 1994, 04 (C4), pp.C4-27-C4-33. 10.1051/jp4:1994404 jpa-00252542

\section{HAL Id: jpa-00252542 https://hal.science/jpa-00252542}

Submitted on 1 Jan 1994

HAL is a multi-disciplinary open access archive for the deposit and dissemination of scientific research documents, whether they are published or not. The documents may come from teaching and research institutions in France or abroad, or from public or private research centers.
L'archive ouverte pluridisciplinaire HAL, est destinée au dépôt et à la diffusion de documents scientifiques de niveau recherche, publiés ou non, émanant des établissements d'enseignement et de recherche français ou étrangers, des laboratoires publics ou privés. 


\title{
Laser-powder-material interactions in the laser cladding process
}

\author{
M. PICASSO ${ }^{(1)}$ and M. RAPPAZ \\ Département de Mathématiques et Laboratoire de Métallurgie Physique, MX-G, Ecole Polytechnique \\ Fédérale de Lausanne, 1015 Lausanne, Switzerland
}

\begin{abstract}
In this paper we present briefly two possible approaches for modelling the laser cladding process. The first approach is $2 \mathrm{D}$ and consists in finding the shape of the molten pool given the fraction of the laser power which is available at the surface of the workpiece and given the amount of powder sticking to the molten pool. The powder reaching the workpiece is assumed to melt instantaneously at the surface of the molten pool, it is then mixed into the molten pool according to the computed velocity field. Because of its complexity, this model is solved only for two-dimensional situations and requires powerfull computers. On the other hand, accurate predictions of the shape of the molten pool are obtained.

The second approach is $3 \mathrm{D}$ and takes into account the interations between the laser beam, the powder particles travelling into the carrier gas and the molten pool. The laser power reaching the surface of the workpiece is estimated and, assuming this power is used to remelt the substrate with the clad being pre-deposited, the melt pool shape is computed using a $3 D$ analytical model, which allows to obtain immediate results, even on personal computers. The predictions obtained with this numerical model are in good agreement with experimental results.
\end{abstract}

\section{INTRODUCTION}

The steady development of high power lasers has encouraged the industrial application of laser surface treatments. Complex components such as turbine blades or engine valves may nowadays be laser processed with either laser remelting or laser cladding treatments $[1,2,3]$.

The aim of the laser cladding process is to deposit a protective layer (from 0.1 to $1.5 \mathrm{~mm}$ ) onto a workpiece and for the two to be joined by a fusion bond. A clad track is obtained by injecting powder particles into the molten pool produced by a moving laser beam. In order to cover areas considerably larger than the diameter

(1) Partially supported by the CERS (Commission pour l'Encouragement de la Recherche Scientifique), Berne, Switzerland and by Sulzer Innotec, Winterthur, Switzerland. 


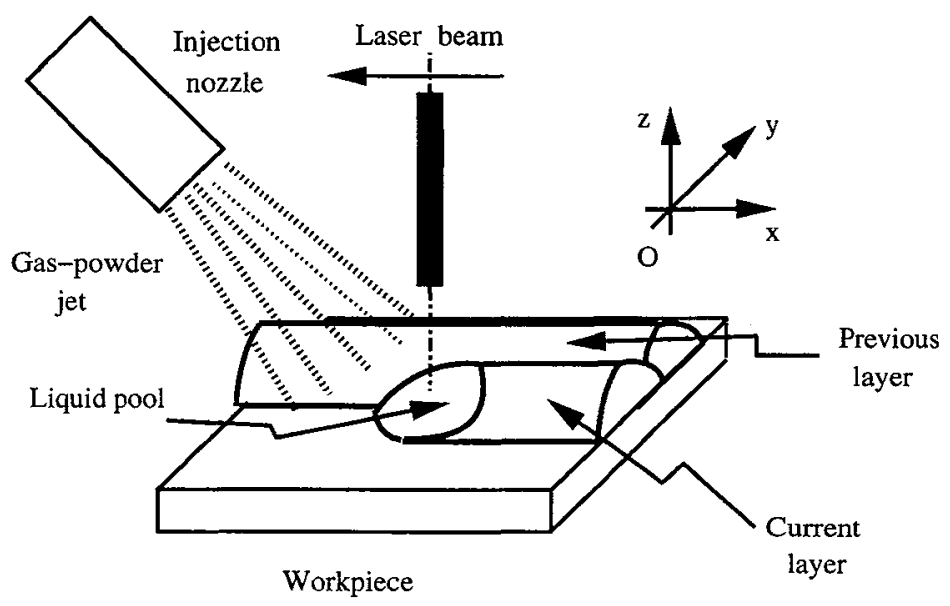

Figure 1: laser cladding.

of the laser beam, successive partially overlapping tracks are deposited (see figure $1)$.

Unlike laser remelting, laser cladding is a difficult process to control because of the interactions between the laser beam, the powder particles and the molten region. Indeed, even if most of the laser power reaches the workpiece, a fraction is captured by the powder particles, thus heating them. Moreover, only the powder particles striking the molten pool adhere, whereas particles hitting the solid region ricochet and are lost. Another complex phenomena is the change of the workpiece absorption (i.e. the ratio between the laser power available at the surface of the workpiece and the power absorbed by the workpiece) with the shape of the molten region. Finally, due to the complex geometry of the clad under the laser beam, it is difficult to predict the laser power which minimizes the depth remelted into the workpiece (either the previous track or the substrate), but still allows melting of the incoming powder.

The processing parameters are numerous. They concern the laser beam properties and velocity relative to the workpiece, the distance between two successive tracks, the geometry of the nozzle used to inject the powder and the injection conditions themselves. These processing parameters are, of course, closely coupled. For instance, changing the beam width requires the distance between two successive tracks to be corrected. It can also be noted that it is possible to obtain clads of the same height at different beam velocities by modifying the amount of powder injected into the molten pool.

To date, few models for cladding have been proposed $[4,5,6]$ and are rather incomplete since they have considered only the heat transfer within the material. In this paper we present briefly two recent models for the laser cladding process $[7,8,9]$. In the first model we focus on the shape of the molten pool given the fraction of the laser energy which is available at the surface of the workpiece and given the 
amount of powder which sticks to the workpiece. The temperature field in the material is computed taking into account the velocity in the molten region but also the deformation of the molten pool due to the powder impact. Numerical results show that the shape of the molten pool, and subsequently the solidification velocity depends strongly upon the parameters of powder injection. The second model aims to provide the correct set of processing conditions in order to achieve a good clad. This model takes into account the interactions between the powder particles and the laser beam, the change of absorption with the shape of the molten pool, and the $3 \mathrm{D}$ aspects of the process. Comparison with experimental results show that this model takes into account the major phenomena involved in the process. A conclusion is outlined at the end of the paper and improvements are proposed for these two models.

\section{A Finite element model to compute the shape of molten pool}

The speed of solidification is an essential data for microstructure calculations, thus special efforts have to be done to predict the shape of the molten pool with accuracy. As for laser remelting, realistic calculations require the velocity field in the molten pool to be computed. In the case of laser cladding the velocity field is driven not only by thermocapillary forces but also by impact and shear due to the powder particles. Unlike the model developped in [6], it is assumed that the powder particles melt instantaneously when reaching the molten pool. Then our model $[7,8]$ consists in solving the enthalpy equation in the workpiece together with the incompressible Navier-Stokes in the region of the molten pool. From the classical mass, momentum and energy conservation principles, the correct boundary conditions are supplied and an equation to account for the deformation of the liquid-gas interface is provided.

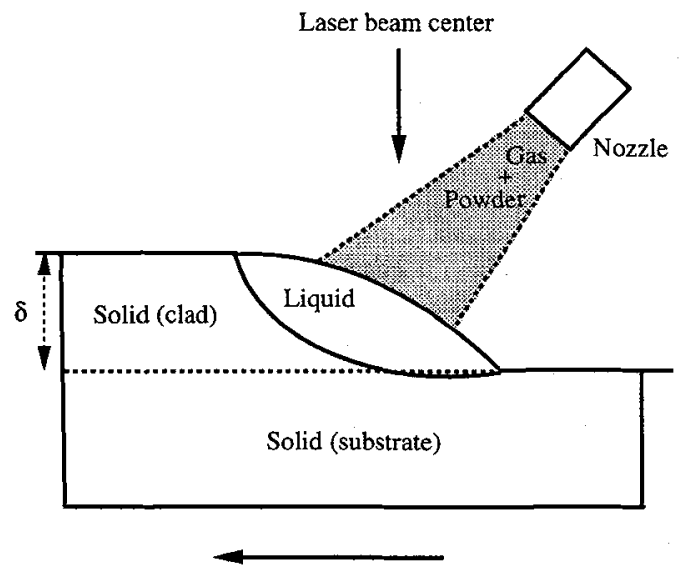

Figure 2: 2D stationary laser cladding.

The algorithm to uncouple the problem is illustrated in figure 3. Given a first guess of the liquid-gas interface, the temperature and velocity field are computed 

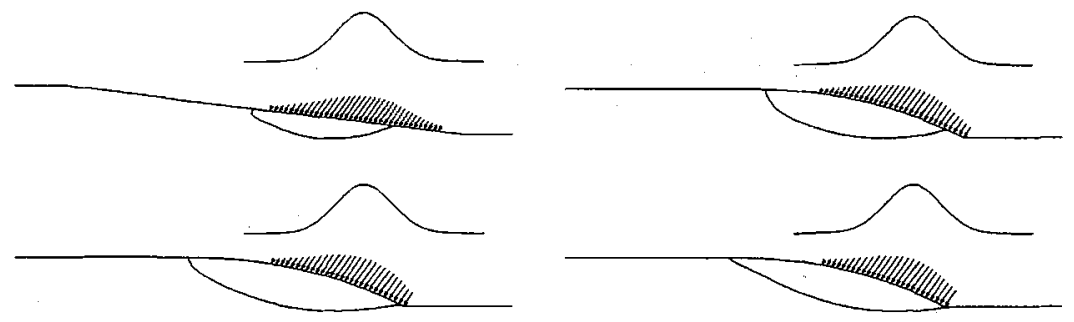

Figure 3: The algorithm

and consequently the shape of the molten pool is known. Then the liquid-gas interface is updated and the process is repeated until convergence is achieved.

The importance of the impact and shear due to the incoming powder is clearly shown in figure 4. Indeed, the streamlines of the velocity field are shown when only the thermocapillary effects are taken into account and when both thermocapillary and powder impact are are taken into account.

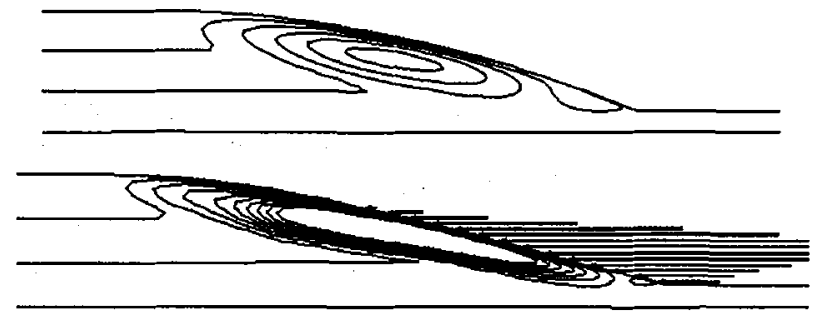

Figure 4: streamlines of the velocity field without powder impact (i.e. only thermocapillary forces) and with powder impact (laser vel. $0.01 \mathrm{~m} / \mathrm{s}$ ).

\section{A simple model to account for the laser, powder and material interactions}

We now present a model which takes into account the major phenomena occuring during the laser cladding process [9]. More precisely we want to provide a tool which can be used by the process engineers to predict the correct processing conditions.

The main idea of this model is to split the laser cladding process into two coupled problems. Firstly, the interactions between the laser beam and the powder particles are considered, thus enabling the laser power which is available at the surface to be estimated. Then the absorption of the workpiece is evaluated according to the molten pool geometry, which allows the power absorbed by the workpiece to be calculated. Secondly, it is assumed that this power is used to remelt the substrate, the clad now being pre-deposited on the surface. Thus, using a 3D analytical model to evaluate the temperature field, the melt pool shape can be computed rapidly [10].

The interactions between the laser beam and the powder particles is described in figure 5. Before the laser beam reaches the workpiece, it passes through the 


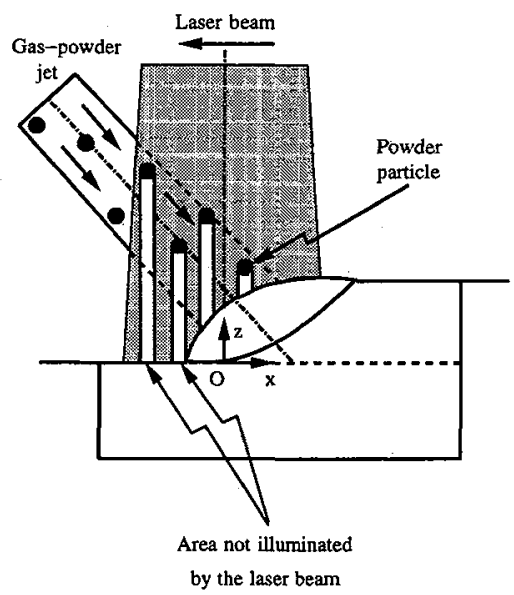

Figure 5: the attenuation of the laser power due to the powder particles.

gas-powder jet which "attenuates" part of the laser power. The powder particles absorb part of the attenuated power; surrendering it to the workpiece only if they strike and enter into the molten pool.

One of the most difficult point of laser cladding is that the overall workpiece absorption depends on the processing conditions. Indeed, experiments $[11,12]$ have shown that the absorption of a laser beam onto an inclined plane depends on the angle of the normal to the plane with respect to the laser beam. Thus, as the powder feed rate is increased with all the other parameters remaining constant, the clad height will increase leading to a greater angle between the normal to the liquid-air interface and the laser beam, thus increasing the absorption of the workpiece.

Experiments with a $1.5 \mathrm{~kW}$ and $5 \mathrm{kWCO} \mathrm{CO}_{2}$ lasers have been carried out and a large data bank of processing conditions, which generate clads without porosity and dilution (dilution being the ratio between the depth remelted to the substrate and the clad height $h_{c}$ ), is available. All the experimental data used in this paper concern the cladding of Stellite- 6 (a cobalt based alloy) onto a mild steel $(0.1 w . t . \% C)$, producing clads with dilution less than $5 \%$. Experimental and numerical results are in quite good agreement with the experiments eventhough there is some discrepancy between the two sets of results. However this model is very encouraging indicating that more complex computations of the melt pool (including the real three dimensional cladding geometry, the non-linear thermal response of the material and the real boundary conditions) must be carried out in the future.

In order to show that our model can really be used to predict the correct processing parameters of the process, we now answer the two following questions :

- is it convenient to have a powerful laser? In other words, a $2 \mathrm{~kW}$ laser being about two times more expensive than a $1 \mathrm{~kW}$ laser, will it be possible to clad more than two times faster?

- for a given clad height what beam radius should be used? 
In order to answer the first question, the computed coverage rate (i.e. the laser velocity times the intertrack step) has been plotted as a function of the laser power for five fixed clad heights. As shown in figure 6 the answer to the first question is positive, encouraging the use of powerful lasers for industrial applications. The answer to second question is given according to the results of figure 7 . The coverage rate has been plotted as a function of the beam radius for five fixed clad heights. Clearly the maximum of the coverage rate is reached when the beam radius is about two times the clad height.

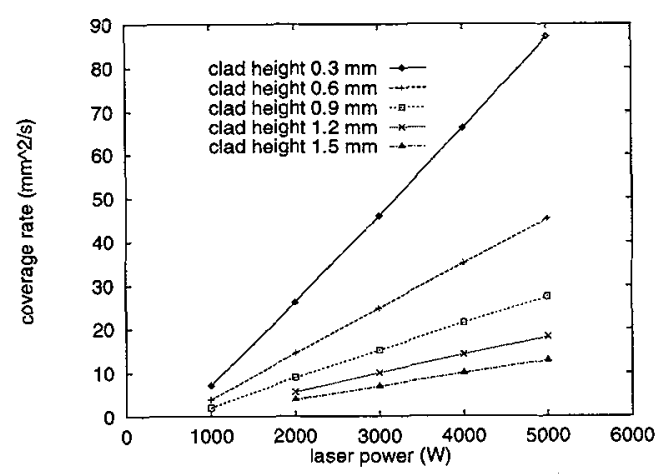

Figure 6: coverage rate against laser power for fixed clad heights.

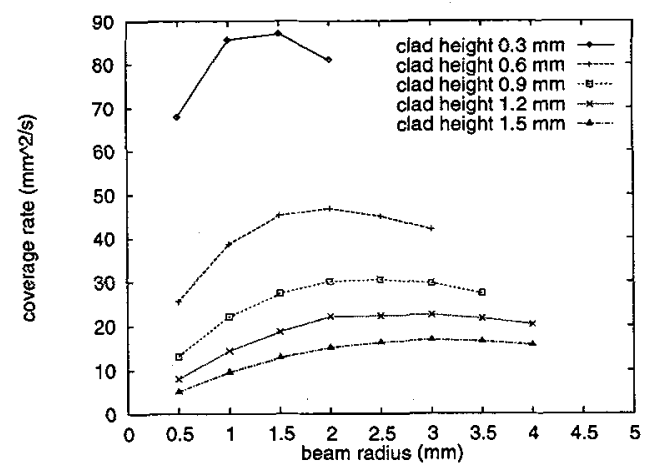

Figure 7: coverage rate against laser beam radius for fixed clad heights.

\section{CONCLUSION}

In this paper two models for the laser cladding process are briefly presented. We refer to $[7,8,9]$ for detailed presentations. The first model is $2 \mathrm{D}$ and aims to compute 
the shape of the molten pool given the fraction of the laser power available at the surface of the workpiece and given the amount of powder sticking to the workpiece. It necessitates a strong knowledge of numerical methods but allows accurate results to be obtained.

The second model is $3 \mathrm{D}$ and considers the major phenomena involved in the process namely the laser-powder-material interactions and allows the correct parameters of the process to be predicted. In order to obtain fast results the shape of the molten pool is determined using an analytical solution, which is a source of discrepancy between computed and experimental results. However results show that all the ingredients are contained in this model in order to obtain correct predictions.

The panacea would be of course to couple these two models. To achieve this goal there are several difficulties we must overcome. Firstly a 3D model analog to the first one has not been developed yet and would involve a strong commitment from a numerical point of vue. Secondly, computations would require large CPU times thus preventing this model to be used by the process engineers. We believe that the next faisable step would consist in solving the enthalpy equation with the $3 \mathrm{D}$ geometry of laser remelting (i.e. the workpiece with finite diemnsions and with the powder predeposited on it), thus including the nonlinear effects of phase-change and the correct boundary conditions in the computations of the molten pool.

\section{REFERENCES}

[1] P.J.E. Monson \& W.M. Steen, Comparison of Laser Harfacing with Conventional Processes, Surface Engineering 6 (1990), 185-193.

[2] D.E. Belfore, Blade Repair time-cut in half, Industrial Laser Review 7(10), 11-13.

[3] M. Kawasaki, K. Takase, S. Kato, M. Nakagawa \& K.Mori, Developments of Engine Valve Seat directly positioned onto Aluminum Cylinder Head by Laser Cladding Process, Proc. Int. Congress and Exposition, Detroit, Mi, feb. 24-28, 1992, S.A.E. Technical Paper Series, 920571, 400 commonwealth dr., Warrendale, $\mathrm{Pa} 15096$.

[4] V.M. Weerasinghe and Steen W.M., Laser Surface Cladding, Laser Surface Treatments of Metals (C.W. Draper and P. Mazzoldi, eds.), Martinus Nijhoff, Dordrecht, 1986, pp. 360387.

[5] A. Kar and J. Mazumder, One-dimensional diffusion model for extended solution in laser cladding, J. Appl. Phys. 61 (1987), 2645-2655.

[6] A.F.A. Hoadley \& M. Rappaz, A Thermal Model of Laser Cladding by Powder Injection, Met. Trans. 23B (1992), 631-643.

[7] M. Picasso, Simulation numérique des traitements de surface par laser, PhD Thesis 1992, Département de mathématiques, Ecole Polytechnique Fédérale de Lausanne, 1015 Lausanne, Switzerland.

[8] M. Picasso \& A.F.A. Hoadley, Finite element simulation of laser surface treatments including convection in the melt pool, Int. J. Num. Meth. Heat Fluid Flow (to appear1994).

[9] M. Picasso, CF. Marsden, J.-D. Wagnière, A. Frenk \& M. Rappaz, A simple but realistic model for the laser cladding process, Met. Trans. B (to appearapril 1994).

[10] H.E. Cline \&z T.R. Anthony, Heat treating and melting material with a scanning laser or electron beam, J. Appl. Phys. 48 (1977), 3895-3900.

[11] C.F. Marsden, A. Frenk \& J.-D. Wagnière, Power Absorption during the Laser Cladding Process, Proc. European Conference on Laser Treatment of Materials (ECLAT'92) (B.L. Mordike, ed.), D.G.M. Informationsgesellschaft, Adenauerallee 21 Oberursel, Germany, 1992, pp. 365-380.

[12] B. Ollier et al., Cladding with Laser Radiation : Properties and Analysis, Proc. European Conference on Laser Treatment of Materials (ECLAT'92) (B.L. Mordike, ed.), D.G.M. Informationsgesellschaft, Adenauerallee 21 Oberursel, Germany, 1992, pp. 687-692. 